\title{
Groundwater Pollution Due to Pesticides and Heavy Metals in North West Bank
}

\author{
Marwan Ghanem ${ }^{1}$, Subhi Samhan ${ }^{2}$, Erick Carlier ${ }^{3}$, Wasim $\mathrm{Ali}^{4}$ \\ ${ }^{1}$ Bir Zeit University, Ramallah, Palestine, West Bank; ${ }^{2}$ Palestinian Water Authority, Ramallah, Palestine; ${ }^{3}$ Polytech Lille, Universite \\ lille1, Lille, France; ${ }^{4}$ Karlsruhe Institute of Technology, Karlsruhe, Germany. \\ Email: mghanem@birzeit.edu, subhisamhan@yahoo.com, Erick.carlier@plytech-lille.fr, wasim.ali@kit.edu
}

Received December 29 $9^{\text {th }}$, 2010; revised February $1^{\text {st }}, 2011$; accepted March $16^{\text {th }}, 2011$.

\begin{abstract}
This study aims at determining the quantitative effect of pesticides including 2, 4-D dichlorphenoxy acetic acids, Paraquat, Atrazine (2-chloro-4-ethylamino-6-isopropylamino-s-triazine), and MCPP 2-(2-Methyl-4-chlorophenoxy) propanioic acid on groundwater quality due to agricultural in Jenin and Tulkarem, northern part of the West Bank. The concentrations of pesticides in Jenin was found to be higher than those in Tulkarem where the majority of the samples taken had concentration $10 \mu \mathrm{g} / \mathrm{L}$. It is concluded that the contamination of the tested wells was due to pesticides and not wastewater disposal, since most of the samples were free from pathogenic indicators. Results revealed that using these wells for drinking purposes has a potentially high health risk. This is mainly due to the uncontrolled industrial and agricultural activity as well as the lack of monitoring. Concentrations of heavy metals including cadmium (Cd), lead $(\mathrm{Pb})$, iron $(\mathrm{Fe})$, zinc $(\mathrm{Zn})$, chromium $(\mathrm{Cr})$ and copper $(\mathrm{Cu})$ were also quantitatively determined for the same period extending from April, 2004 to May, 2005. Concentrations of $\mathrm{Pb}$ and $\mathrm{Cr}$ in most of the tested wells in Tulkarem complied with the WHO guideline; while nitrate $\left(\mathrm{NO}_{3}\right)$ and potassium $(\mathrm{K})$ concentrations exceeded the permissible concentrations.
\end{abstract}

Keywords: Pesticides, Groundwater Pollution, Water Quality, West Bank

\section{Introduction}

There are 123 types of pesticides used in the West Bank, 14 of which were internationally suspended, cancelled or banned by WHO. Pesticides are imported to the West Bank and there is no control over their quality, quantity, health and environmental effect [1]. This multiplies the impact of pesticides and makes it difficult to control or monitor. Industrial waste is discharged on sensitive recharge zones adversely impacting the groundwater in the area [2]. This initiates the necessity to monitor the groundwater quality in terms of the concentration of pesticides and heavy metals. The sorption of pesticides by solid material and its resulting influence on its biodegradation is also important to be taken into consideration when measuring its impact on the groundwater.

Research is required to measure the concentration of toxic substances such as pesticides and trace elements that affect human health, mainly those that need time for biodegradation and depend on environmental conditions such as soil composition, depth to water table, land use, and other weathering factors such as temperature, humid- ity, rainfall intensity and land slope. Several surveys conclude that large quantities of pesticides are used per cultivated crop area. Accordingly, it is recommended to study and analyze agricultural and wastewater indicators that when available in concentrations exceeding the permissible guidelines have adverse impact on human health and wellbeing.

\section{Research Objectives}

This study aims to determine the concentration of pesticides in groundwater due to agricultural activity in addition to the concentration of trace elements originating from the disposal of industrial wastes in dumping sites. The study area is located in Jenin and Tulkarem in the northern part of the West Bank. The impact of these pollutants on human health due to their low biodegradability and accumulation of organics and traces compounds was also determined.

\section{Methodology}

Fifty water samples were collected from groundwater wells in three sampling campaigns. Preservation, extrac- 
tion, and analysis were done every three months in order to investigate the increment or absence of pesticides and heavy metals in the tested wells, noting that $10 \%$ of the wells were double-sampled for Quality Control (QC)/ Quality Assurance (QA). The analyses of the pesticides and trace elements were carried out according to the Standard Methods [3]. The samples were collected from 13 representative groundwater wells in Tulkarem and Jenin. The samples were analyzed for the organic species of pesticides including 2, 4-D dichlorphenoxy acetic acids, Paraquat, Atrazine (2-chloro-4-ethylamino-6-isopropylamino-s-triazine), and MCPP 2-(2-Methyl-4-chlorophenoxy) propanioic acid. Moreover; traces elements and heavy metals including cadmium $(\mathrm{Cd})$, lead $(\mathrm{Pb})$, iron $(\mathrm{Fe})$, zinc $(\mathrm{Zn})$, chromium $(\mathrm{Cr})$ and copper $(\mathrm{Cu})$ were analyzed. Results were analyzed and compared to international standards and guidelines (Table 1).

\section{Background}

\subsection{Water Resources}

Twenty sixth percent of an average rainfall of $450 \mathrm{~mm}$ per year is considered as the main replenishment source for the underlying aquifer system [4]. The study area overlies the Cenomanian-Turonian Aquifers of the Western Aquifer Basin (WAB) and Northeastern Aquifer Basin (NAB) (Figure 1).

NAB flows to the east towards the Jordan River, located in the large syncline of the north-central part of the West Bank covering most of Jenin in the northern part of the Mountain Belt in an area that is generally flat with rolling hills and no obvious topographic features to delineate its boundaries. The North Eastern Aquifer (NEA) is formed from two main aquifer basins: The Shallow Aquifer (from the Eocene age) and the Deep Aquifer (of the Turonian-Upper Cenomanian age), separated by a chalk layer of Senonain age. Based on the exposure of the formations; the natural recharge is estimated to be around $130 \mathrm{MCM} / \mathrm{year}$. The yearly abstraction estimated from the associated wells is estimated to be about $27 \mathrm{MCM}$ /year [5]. Groundwater quality in the Basin has shown some deterioration over time, primarily due to surface contamination from wastewater and unsustainable agricultural practices [6].

The WAB lies under the western part of the West Bank Mountains underlying and flows to the west towards the Mediterranean Sea. WAB is formed of two main aquifers: the Upper Aquifer (Turonian-Upper Cenomanian age) and the Lower Aquifer (Lower Cenomanian to Upper Albian age) separated by a marly aquitard called the Yatta formation. The average thickness of these aquifers ranges from 600 to 900 meters. Based on the exposure of the geologic formations, the average annual natural recharge for the Basin is around 335 - $370 \mathrm{MCM}$ /year [5].

\subsection{Soil and Groundwater Pollution}

Soils in the studied areas can mainly be classified as being Grumusols, and Pale Randzisan Terra Rossa and Brown Rendzinas which are degraded as a result of many factors including erosion, acidification and salinization due to both anthropogenic (man-made) and non-anthropogenic (natural) causes. The main natural cause is the change in climatic conditions in the area(rainfall and temperature), while man-made causes include socio-economic

Table 1. The international standards guideline and their instrumentation detection limit.

\begin{tabular}{|c|c|c|c|}
\hline Parameters* & Detection limits* & Benchmark & Regulator \\
\hline Iron $(\mathrm{Fe})$ & 100 & 1000 & $\mathrm{WHO}^{* * *}$ \\
\hline Cobalt (Co) & 2 & - & WHO*** \\
\hline Cadmium (Cd) & 10 & 3 & $\mathrm{WHO} * * *$ \\
\hline Lead (Pb) & 10 & 10 & WHO*** \\
\hline Zinc (Zn) & 100 & 3000 & WHO*** \\
\hline Chromium (Cr) & 50 & 50 & WHO*** \\
\hline Copper (Cu) & 50 & 2000 & $\mathrm{WHO} * * *$ \\
\hline $2,4 \mathrm{D}$ & 1 & 100 & WHO*** \\
\hline Paraquat & 50 & 150 & WHO*** \\
\hline Atrazine & 10 & 2 & $\mathrm{WHO}^{* * *}$ \\
\hline
\end{tabular}

*Unit in $\mu \mathrm{g} / \mathrm{l}$ for the analyst. **EPA (Environmental Protection Agency). ***WHO, 1998 (World Health Organization). 


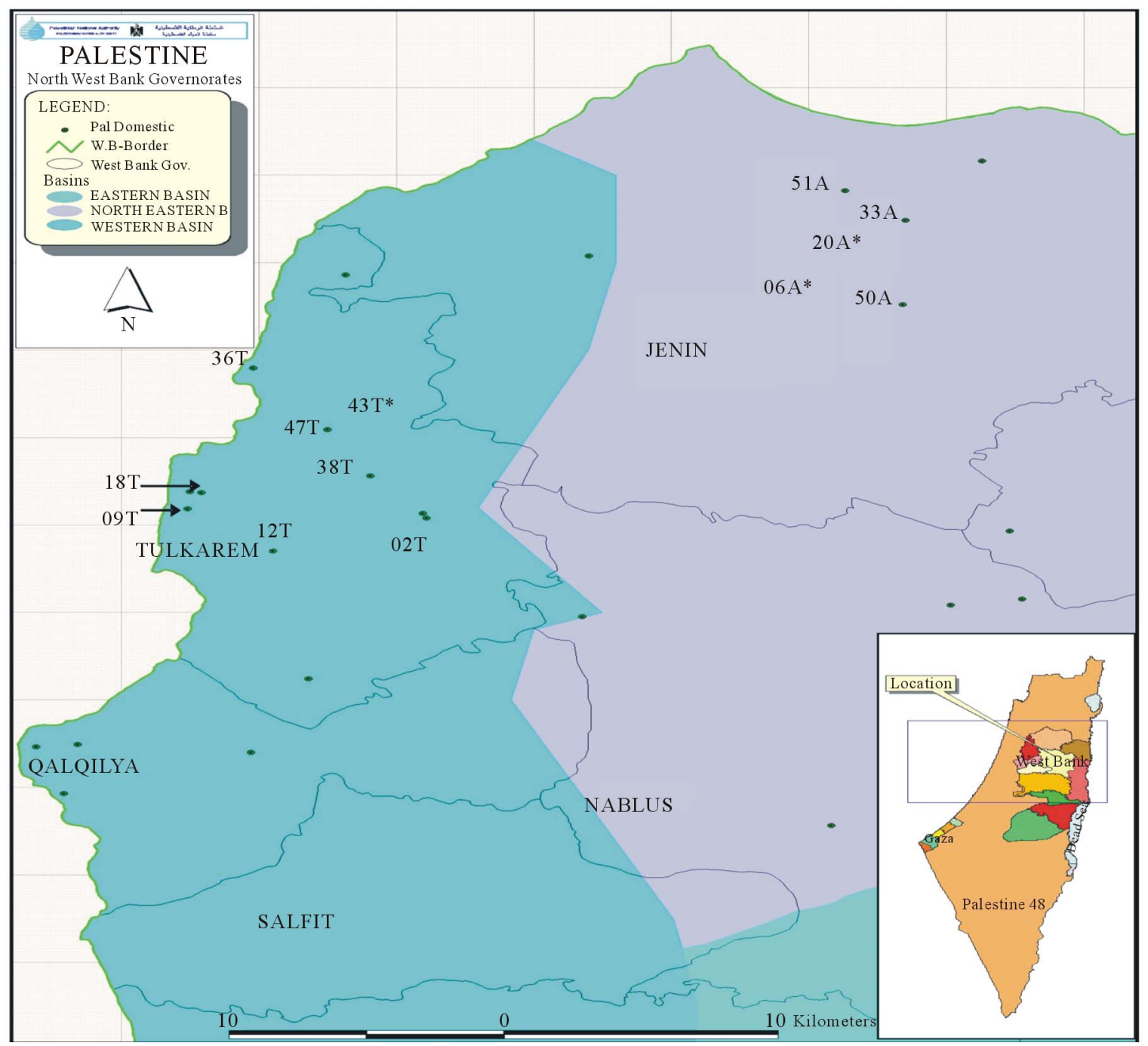

Figure 1. Representative sampling points in the study area in Tulkarem and Jenin. The numbers are representing sampling points.

factors, existing land uses and use of organic and inorganic material in agricultural activity. Soil and groundwater pollution is caused mainly by agricultural practices (notably the use of inorganic fertilizers and pesticides), localized industrial activities (organic pollutants, heavy metals), and inadequate or improper disposal of wastewater and solid waste (including hazardous materials). Pesticides are used in large quantities in Tulkarem and Jenin [7]. These include chemicals imported and used illegally, despite of long-standing international bans. For example, soil sterilizing with methyl bromide is officially banned, yet still practiced extensively in greenhouse farming in Tulkarem and Jenin [7]. Groundwater contamination depends on land use, local soil and geological conditions. Since limestone outcrops over the study area, this facilitates the penetration of substances increasing the aquifer's vulnerability to contamination.

\subsection{Climate}

The climate of Tulkarem and Jenin as the rest of the West Bank is affected by diverse ranges in topography and altitude and is influenced by the Mediterranean environment which is characterized by long, hot, dry summers and short, cool, rainy winters. The average annual precipitation in Tulkarem is estimated at $642 \mathrm{~mm}$ for the period extending from 1952 to 2006 with a total of rainy days ranging from 57 to 75 during 1995-2006. The average annual maximum relative humidity values was estimated to be about $75.9 \%$ in February while the lowest value was in May at about 62\% during 1995-2004. The average annual maximum temperature was recorded to be $22.3^{\circ} \mathrm{C}$ and the mean annual minimum temperature was $15.6^{\circ} \mathrm{C}$ [8]. The average annual precipitation in Jenin is $528 \mathrm{~mm}$. The average yearly temperature is $27.1^{\circ} \mathrm{C}$, 
while the average minimum temperature is $13.5^{\circ} \mathrm{C}$ and the mean annual humidity is $67.2 \%$ during the winter [9].

\subsection{Geography and Geology}

Tulkarem has a highly varying topography; with the highest point at $500 \mathrm{~m}$ above sea level and the lowest at $40 \mathrm{~m}$ above sea level. The same goes for Jenin that has a peak height of $750 \mathrm{~m}$ above sea level while the lowest level is at $90 \mathrm{~m}$ above sea level. In terms of geology, the majority of the Tulkarem and Jenin area is rocky mainly comprised of carbonate sediment such as limestone, carbonate, chalk and marl. The geological rock age formations range from Cretaceous to Quaternary.

\section{Discussion}

\subsection{MCPP, 2, 4-D and Atrazine}

Environmental pollution arises through inadequate disposal practices of various amounts of organic compounds from agricultural activities that are applied and distributed in the general environment through the air, water and soil, particularly during periods of rain, high winds, or high temperature. 2, 4-D and its derivatives characterized by alkali or amine salts used as agricultural herbicides against broad-leaf weeds in cereal crops as well as on pastures and lawns are fairly rapidly broken down by hydrolysis, photolysis, and by biological action. Persistence or accumulation of 2, 4-D residues from normal use is occasionally possible, mainly under dry or cold conditions where there is little biological activity [10]. Consequently leading to the contamination of water sources used for irrigation and drinking purposes.

There is no data about the environmental fate of the impurities present in 2, 4-D herbicides. In general, 2, 4-D residues in surface water were found to be less than $0.1 \mu \mathrm{g} / \mathrm{l}$. This is not unexpected, according to the relatively rapid biodegradation of 2, $4 \mathrm{D}$ in the environment [11].

Atrazine is an herbicide used for weed control which is largely used in the study area with different commercial names. Atrazine is adsorbed or dissolved with organic matters which result in enhanced aqueous solubility therefore, enhancing the mobility of Atrazine. Most of the decrease in Atrazine concentration in the root zone over time could be attributed to leaching and degradation during the study period [12]. The concentrations of 2, 4-D and Atrazine in the collected samples are less than the permissible guidelines set at 100 and $2 \mu \mathrm{g} / \mathrm{l}$ respectively (Figure 2) and had different distribution trends. The shallower water table in the wells of Jenin compared to that in Tulkarem increases the risk of using the water for domestic purposes especially without monitoring organic compounds.
Results showed that most of the analyzed samples did not contain Parquet or contain amounts less than the international guideline standard $(100 \mu \mathrm{g} / \mathrm{l}$ according to EPA -2). Results for MCPP, considered as an indicator for the most common herbicides, are shown in Figure 3.

Results of MCPP concentrations revealed that there is a direct relation between depth and the presence of organic accumulation in the tested wells, this supports and correlates the presence of nitrate and its incremental to MCPP in acid form in high amounts.

\subsection{Heavy Metals}

Analyses of heavy metals are rarely done in the West Bank for monitoring purposes. The result for $\mathrm{Pb}$ was greater than the WHO guideline [10] set at $10 \mu \mathrm{g} / \mathrm{l}$. While $\mathrm{Cr}$ and $\mathrm{Cd}$ were found in concentrations around the WHO guideline of 50 and $3 \mu \mathrm{g} / \mathrm{l}$ respectively. The $\mathrm{Cr}$ and $\mathrm{Pb}$ concentrations show fluctuations above and below the WHO standard [10] (Table 1), hence; both are considered as sources of pollution caused by industry and arbitrary dumping sites that deteriorates the groundwater (Figure 4).

Concentrations of heavy metals varied both spatially and temporally and were distributed in a way in which it is more crucial in the wells in Jenin compared to those in Tulkarem (Figure 5), since the depths to the water table are shallower compared to those in Tulkarem.

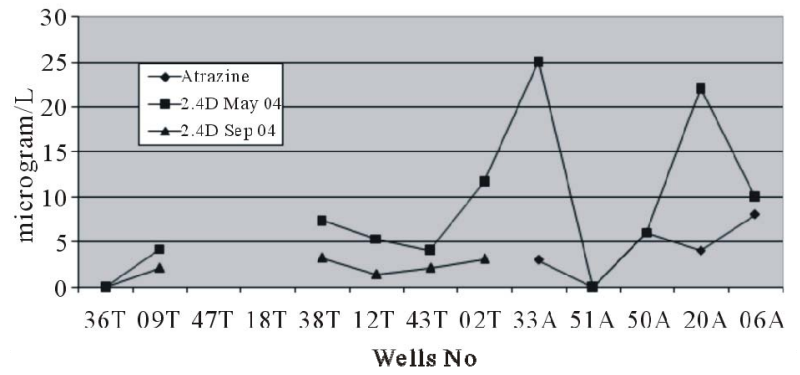

Figure 2. The concentrations of 2, 4-D and Atrazine in the study area.

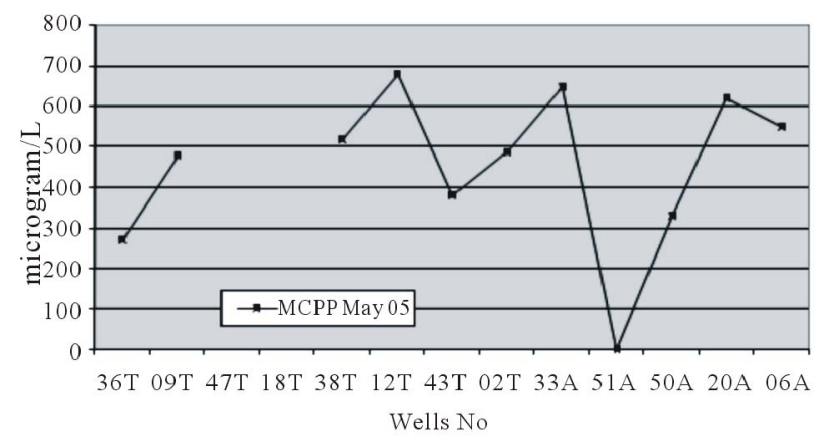

Figure 3. The concentrations of MCPP in the groundwater wells in the study area. 


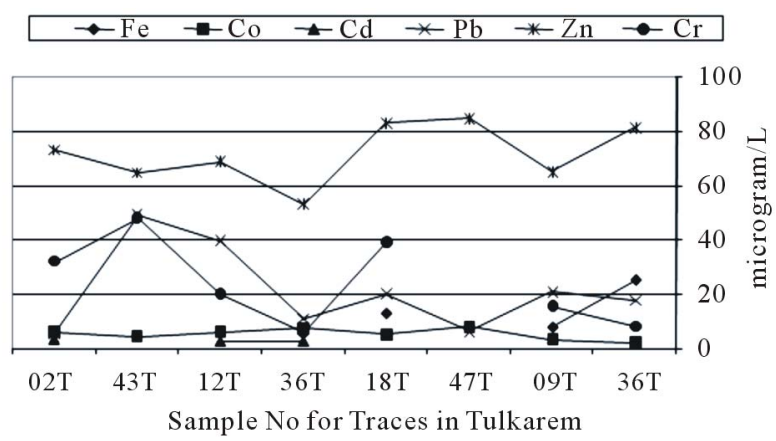

Figure 4. The concentrations of the trace elements in Tulkarem area.

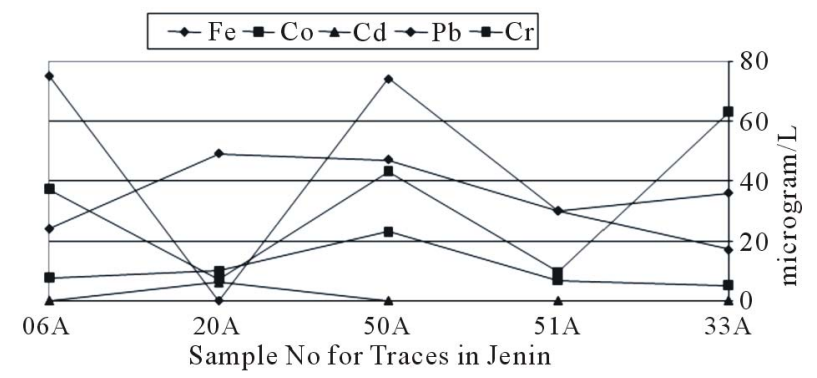

Figure 5. The concentrations of the trace elements in Jenin area.

\subsection{Nitrate, Potassium and Depth}

The results illustrate that there is a direct relation between the depth and the concentration of nitrate due to practices and activities on the ground mainly being the use of fertilizers. Nitrate levels in the groundwater are found to be above the WHO guideline values due to fertilizers making the sources unfit for drinking purposes (i.e. $>50 \mathrm{mg} / \mathrm{liter}$ ). The same goes for potassium incremental and accumulation. In most of the cases the tested sources bacterial pollution was absent further justifying that the nitrate and potassium incremental are due to the extensive use of fertilizers. The accumulation of organic substances and heavy metals were verified by comparing between nitrate and potassium incremental results and well depths as in Figure 6.

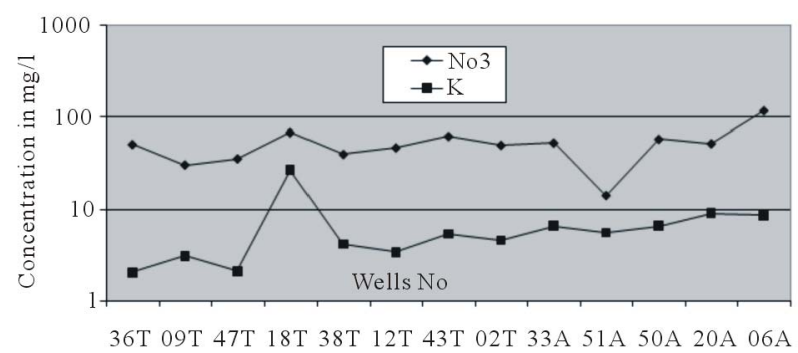

Figure 6. Variations of $\mathrm{NO}_{3}$, $\mathrm{K}$ versus depth in Tulkarem and Jenin groundwater wells.

\section{Conclusions}

Analysis results indicate that the nitrate and potassium increment in shallow wells makes the sources unfit for domestic consumption. This is mainly due to agricultural activities and the use of fertilizers. Results revealed that Parquet was not found in the tested wells since it has only been introduced and used very recently. Heavy metals were also investigated in the two areas; cationic parameters can be easily exchanged in the complex compounds as aligned. In Tulkarem there was no significant pollution from the trace elements mainly $\mathrm{Pb} 90 \%$, Cd $20 \%$ and $\mathrm{Cr} 35 \%$. On the other hand, in Jenin about 85\% of the tested samples were polluted with $\mathrm{Pb}$. The effects of these pollutants on human health due to the low biodegradability and accumulations of organics and trace compounds must also be determined.

\section{Recommendations}

It is recommended to control and restrict the agricultural and industrial activity in both areas in order to prevent the leachate from reaching the groundwater. Pesticides and mainly those containing a halogen-carbon bond should be investigated in the future. It is also recommended to initiate a pilot scale study for chlorinated water and controlling the organic indicators of Total Organic Carbon (TOC) and Dissolved Organic Carbon (DOC). Raising the awareness of all relevant institutions working in the fields of environmental pollution and discussing water treatment issues for the future is strongly recommended.

\section{REFERENCES}

[1] A. A. Qare, "Potential Leaching of Pesticides to GroundWater: A Look At The Most Common Use Pesticides In Palestine," Proceedings of the 2nd International Conference on Water: Values and Rights, Ramallah, 13-15 April 2009.

[2] A. Saleh, F. Neiroukh, O. Ayyash and S. Gasteyer, "Pesticide Usage in the West Bank,” Applied Research Institute of Jerusalem, 1995.

[3] American Public Health Association (APHA), "Standard Methods for the Examination of Water and Wastewater," 19th Edition, Washington DC, 1995.

[4] Water Resources Action Programme (WRAP), "Palestinian Water Resources, a Rapid Interdisciplinary Sector Review and Issues Paper,” Report, Palestine, 1994.

[5] Palestinian Water Authority (PWA), "Water resources and Planning,” Unpublished data, West Bank, 2006.

[6] A. A. Rabbo, D. J. Scarpa, Z. Qanam, Q. A. Jaber and P. Younger, "Wells in the West Bank, Water Quality and Chemistry,” Palestinian Hydrology Group, University of Newcastle upon Tyne and Bethlehem University, Jerusalem, West Bank, 1999.

[7] Applied Research Institute of Jerusalem (ARIJ), "Status 
of the Environment in the Occupied Palestinian Territory,” Bethlehem ,West Bank, 2007.

[8] Tulkarem Agricultural Department, "Meteorological Data about Tulkarem Governate,” Unpublished data, Tulkarem, West Bank, 2006.

[9] Jenin Agricultural Department, "Meteorological Data about Jenin Governate," Unpublished data, Jenin, West Bank, 2004.

[10] World Health Organization (WHO), "Guidelines for
Drinking-Water Quality,” 2nd Edition, WHO publications, Geneva, 2006.

[11] World Health Organization (WHO), "Environmental Health Criteria 29: 2, 4-Dichlorop-Henoxyacetic Acid (2, 4-D),” WHO publications, Geneva, 1984.

[12] J. Masalha, J. Hassan, and C. El-Ama, "Effect of Effluents on Atrazine Leaching," Proceedings of Palestinian Academy Conference, Ramallah, Vol. 1, 2005, pp. 264-274. 